\title{
Impelementasi Cerita Rakyat melalui Mata Kuliah Pendidikan Seni Tari Usia Dini untuk Meningkatkan Kreativitas Pada Mahasiswa PG-PAUD FKIP UNSRI
}

\author{
Hasmalena $^{1 凶}$, Mahyumi Rantina ${ }^{2}$ \\ PG-PAUD, FKIP, Universitas Sriwijawa Palembang
}

\begin{abstract}
Abstrak
Permasalahan pada penelitian ini adalah belum berkembangnya kretivitas mahasiswa PG-PAUD UNSRI. Tujuan dalam penelitian ini adalah untuk meningkatkan kreativitas pada mahasiswa PGPAUD FKIP Unsri. Jenis penelitian yang digunakan yaitu penelitian tindakan dengan model Kemmis dan Taggart yang dilakukan sebanyak 4 kali pertemuan. Subjek dalam penelitian ini sebanyak 40 orang terdiri dari 38 orang perempuan dan 2 orang laki-laki. Data dikumpulkan dengan observasi, wawancara, dan dokumentasi dengan menggunakan teknik analisa data secara deskriptif kualitatif. Hasil penelitian menunjukan bahwa dengan cerita rakyat dalam mata kuliah seni tari dapat meningkatkan kreativitas, terbukti dengan pengamatan yang dilakukan telah mencapai indikator keberhasilan 75\%. Pada siklus 1 pertemuan 1 aspek kelancaran berada pada kategori 63,33\%, keluwesan berada pada kategori 58,33\%, orginalitas berada pada kategori 54,16\%, mengelaborasi berada pada kategori 55,83\%, sistematis berada pada kategori 57,5\%. Kedua pada siklus pertama pertemuan kedua, pada aspek kelancaran sebesar 66,66\%, aspek keluwesan sebesar 71,66\%, aspek orginalitas sebesar 74,16\%, mengelaborasi sebesar 72,5\%, sistematis sebesar 69,16\%. Ketiga pada siklus 2 pertemuan 1 pada aspek kelancaran sebesar 79,16\%, keluwesen sebesar $75 \%$, originalitas sebesar $77 \%$, mengelaborasi sebesar 78\%, sistematis sebesar 83\%. Keempat pada siklus 2 pertemuan 2, aspek kelancaran sebesar $80 \%$, keluwesan sebesar $80,83 \%$, orginalitas sebesar $80,83 \%$, mengelaborasi sebesar $84,16 \%$, dan pada aspek sistematis sebesar $85 \%$. Hasil penelitian tersebut menunjukan bahwa dengan cerita rakyat dalam mata kuliah seni tari dapat meningkatkan kreativitas pada mahasiswa PGPAUD FKIP Unsri
\end{abstract}

Kata Kunci: cerita rakyat, seni tari anak, kreativitas

\section{Abstract}

The purpose of this research is to improve the creativity students of PG-PAUD FKIP Unsri. The type of research used is action research with Kemmis and Taggart model conducted 4 meetings. Subjects in this study as many as 40 people consisting of 38 women and 2 men. Data were collected by observation, interview, and documentation by using qualitative descriptive data analysis technique. The results showed that with folklore in dance courses can increase creativity, as evidenced by the observations made have achieved $75 \%$ success indicator. In the 1st cycle of the meeting 1 aspect smoothness is in category $63,33 \%$, flexibility is in category $58,33 \%$, orginality are in category $54,16 \%$, elaborate is in category $55,83 \%$, systematic is in category $57,5 \%$. Second in the first cycle of the second meeting, the smoothness of $66.66 \%$, the flexibility aspect of $71.66 \%$, orginality aspect of $74.16 \%$, elaborate $72.5 \%$, systematic by $69.16 \%$. Third on cycle 2 of meeting 1 on the smoothness aspect of $79,16 \%$, variable $75 \%$, orginalitas $77 \%$, elaborate by $78 \%$, systematic equal to $83 \%$. Fourth in cycle 2 of meeting 2, smoothness aspect $80 \%$, flexibility $80,83 \%$, orginality $80,83 \%$, elaborate $84,16 \%$, and systematic aspect equal to $85 \%$. The results of this study show that with folklore in the art of dance can improve creativity in students PG-PAUD FKIP Unsri.

Keywords: folklore, the childhood dance art, creativity.

@ Jurnal Obsesi Prodi PG-PAUD FIP UPTT 2017

$\triangle$ Corresponding author :

Address : Palembang Sumatera Selatan

Email : lena.bunda@yahoo.co.id

ISSN 2356-1327 (Media Cetak)

ISSN 2549-8959 (Media Online) 


\section{PENDAHULUAN}

Pendidikan nasional berfungsi dalam mengembangkan dan membentuk watak serta peradapan bangsa yang bermartabat dalam mencerdaskan kehidupan bangsa, bertujuan untuk berkembangnya potensi peserta didik agar menjadi manusia yang beriman, bertaqwa, berakhlak mulia, sehat, berilmu, cakap, kreatif, mandiri dan menjadi warga yang demokratis dan bertanggung jawab (Martini, 012:24). Pendidikan seni tari merupakan mata kuliah yang dapat merangsang kreativitas mahasiswa. Pendidikan melalui seni tari memiliki peranan kunci dalam merangsang kreativitas.

Pendidikan merupakan faktor utama dalam membangun bangsa dan Negara, sehingga dalam hal ini Negara Indonesia memberikan perhatian sungguh-sungguh terhadap jalannya pendidikan, dengan mengalokasikan dana APBN sebesar 20\% untuk pendidikan. Adanya perhatian dari semua pihak menuntut dunia pendidikan perlu ditingkatkan agar menghasilkan sumbar daya manusia yang berkualitas.

Pendidikan merupakan suatu kegiatan untuk mengendalikan "learning" guna mencapai tujuan yang direncanakan mahasiswa secara efektif dan efesien. Dalam proses kegiatan ini peranan "teaching" amat penting karena merupakan kegiatan yang dilakukan oleh guru untuk mentransfer pengetahuan, keterampilan dan nilai kepada mahasiswa/siswa, sehingga apa yang ditransfer memiliki makna bagi diri sendiri dan berguna bagi dirinya dan masyarakat. Mengajar yang baik dan benar hanya dapat dilakukan oleh seseorang yang telah melewati pendidikan tertentu yang memang dirancang untuk mempersiapkan menjadi guru, dengan kata lain, mengajar merupakan suatu profesi (Zamroni,2000;12)

Dalam proses belajar mengajar, pendidik sebaiknya menggunakan metode yang bervariasi agar proses pengajaran tidak membosankan. Bercerita merupakan salah satu cara mengajar untuk menanamkan kebiasaankebiasaan yang baik. (Fauziddin, 2017)

Selain dengan cerita, pembelajaran dengan menggunakan seni juga sangat menarik perhatian anak sehingga tidak membosankan.
Salah satu kemampuan yang dikembangkan adalah kreativitas.

Kreativitas merupakan kemampuan menciptakan sesuatu yang baru, proses konstruksi ide yang dapat diterapkan dalam menyelesaikan masalah, serta suatu kegiatan yang bermanfaat baik diri sendiri, maupun orang lain. Kreativitas perlu dipupuk dan dikembangkan melalui pendidikan seni tari yang mengajak mahasiswa untuk kreatif, sebagai contoh bercerita di depan mereka kemudia meminta mereka untuk mengekplor gerak sesuai dengan tokoh yang ada pada cerita tersebut yang nantinya dapat mereka kembagkan menjadi sebuah tarian, dengan begitu kita telah memberikan kebebsan pada mereka untuk membuat sesuatu dengan kreativitas mereka.

Berdasarkan pengematan dapat dilihat bahwa mahasiswa PG-PAUD FKIP Unsri belum bisa berkreativitas menipta dan mengembangkan cerita rakyat melalui pendidikan seni tari dalam pembelajaran, dalam mngkreasiakan senintari untuk anak usia dini mahasiswa masih terfokus kepada contohcontoh yang sudah ada. Padahal di Sumatera Selatan banyak sekali terdapat cerita rakyat yang merupakan gambaran dari budaya dan adat istiadat. Disetiap daerah mencerminkan cerita dari ciri khas yang berbeda-beda yang mencirikan kebiasaan hidup mulai dari tata cara bersosial, budaya, ritual dari cerita rakyat tersebut. Dari cerita rakyat tersebut mahasiswa diberikan kebebasan untuk memilih cerita rakyat dari daerahnya masing-masing dan mengembangkan kemampuan untuk berkreasi mengkonstruk pengetahuan yang mereka miliki tentang cerita rakyat kemudian menunjukan dengan gerak tari.

Permasalahan dalam penelitian ini adalah bagaimana implementasi cerita rakyat melalui pendidikan seni tari untuk meningkatkan kreativitas pada mahasisa PGPAUD FKIP Unsri.

Sedangkan Tujuan dalam penelitian untuk merangsang mahasiswa berkreativitas mencipta dan mengembangkan cerita rakyat melalui pendidikan seni tari dan untuk melihat 
pross pembelajaran seni tari dalam meningkatkan keativitas mahasiswa.

PG-PAUD merupakan suatu lembaga pendidikan tempat mempersiapkan seseorang menjadi guru di tingkat awal yaitu Pendidikan Mahasiswa Usia Dini, sudah seharusnya dapat menghasilkan guru PAUD yang dapat mengajar dengan kreativitas yang tinggi. Guru PAUD merupakan guru kelas yang harus dapat mengajarkan berbagai perkembangan pada mahasiswa di kelas tempat ia mengajar, salah satu diantaranya adalah pendidikan seni tari untuk mahasiswa usia dini yang harus dikenalkan sesuai dengan tingkat perkembangan mahasiswa didik.

Pendidikan Seni Tari bertujuan agar peserta didik memiliki kemampuan sebagai berikut: 1) memiliki pengetahuan tari untuk mahasiswa usia dini 2) memiliki pengetahuan prosedural mendesain dan menyusun tari kreatif mahasiswa,

3) mengembangkan desain model pembelajaran tari kreatif mahasiswa 4) mengaplikasikan desain model pembelajaran tari kreatif mahasiswa usia dini dalam kegiatan pembelajaran di sekolah.

Kreativitas adalah kemampuan seseorang untuk melahirkan sesuatu yang baru baik berupa gagasan maupun karya nyata yang relatif berbeda dengan apa yang telah ada sebelumnya. Dengan demikian kreativitas merupakan kemampuan untuk memberi gagasan- gagasan baru yang dapat diterapkan dalam pemecahan masalah (Munandar 1999: 33). Sejalan dengan pendapat di muka, kreativitas itu ibarat sebuah intan. Semakin diasah, semakin berkilau. Seseorang mampu menciptakan sesuatu yang baru dapat diasah dengan stimulasi, dan modal kreatif seseorang adalah pada berfikir (Muhammad 2010: 77).

\section{METODE PENELITIAN}

Metode penelitian yang digunakan dalam penelitian ini adalah dengan menggunakan metode "action research". Desain tindakan/ rancangan dalam penelitian ini menggunakan model Kemmis dan Taggart. Yang terdiri dariempat tahapan yaitu: 1)
Perencanaan, 2) Tindakan, 3) Pengamatan, 4) Refleksi (Arikunto, 2010:17).

Teknik pengumpulan data dengan menggunakan teknik pengumpulan data non tes yang terdiri dari obeservasi, wawancara, catatan lapangan, dan dokumentasi terhadap kegiatan yang sedang berlangsung berkenaan dengan kegiatan pembelajaran di dalam kelas.

Teknik analisa data yang digunakan adalah analisa data kuantitatif dan analisa data kualitatif. Analisa data kuantitatif dilakukan terhadap peningkatan kreativitas melalui pendidikan seni tari pada mahasiswa PGPAUD semester III. Pada setiap siklus, hasil observasi dan refleksi akhir dilakukan untuk mengetahui apakah pendidikan seni tari dapat meningkatkan kreativitas pada mahasiswa secara signifikan.

Sedangkan analisa data kuantitatif adalah dengan menganalisis data yang terjadi dalam proses pembelajaran melalui pendidikan seni tari semenjak observasi awal sampai dengan pelaksanaan siklus dengan prosedur pelaksanaan yang meliputi: perencanaan, pelaksanaan, observai dan refleksi.

\section{HASIL DAN PEMBAHASAN SIKLUS 1 \\ Pertemuan 1}

Pada tindakan pertama ini mahasiswa diberikan pengethuan tentang karya seni tari anak dan diberi penugasan masing-masing kelompok untuk mengapresiasi karya seni tari anak dengan melihat tayangan video tentang tari anak dan hasil kreativitas mahasiswa.

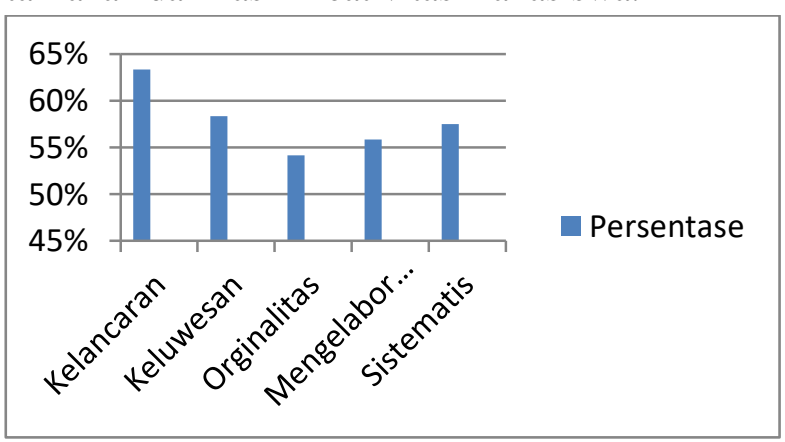

Gambar 1.1 Grafik Peningkatan Kreativitas Mahasiswa PG-PAUD FKIP Unsri

Gambar 1.1 menggambarkan tentang persentase kreativitas pada mahasiswa PGPAUD FKIP Unsri. Pada gambar tersebut 
terlihat persentase pada aspek kelancaran sebesar 63,33\%, aspek keluwesan sebesar $58,33 \%$, aspek orginalitas sebesar 54,16\%, aspek mengelaborasi sebesar 55,83\%, dan aspek sistematis sebesar $57,5 \%$. Pada siklus pertama pertemuan pertama ini aspek yang paling tinggi adalah kelancaran.

\section{Pertemuan 2}

Pada siklus 1 pertemuan kedua mahasiswa telah mencoba praktik langsung mencipta gerakan tari berdasarkan unsur dasar tari, menggolongkan hal-hal menurut kategori yang berbeda, memberikan penafsiran terhadap gerak tari. Berikut ini adalah hasil pengematan pada siklus 1 pertemuan kedua:

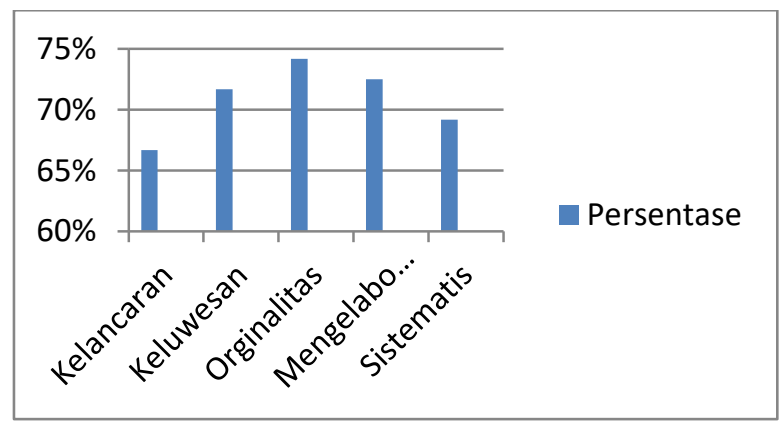

Gambar 1.2.Grafik Peningkatan Kreativitas Mahasiswa PG-PAUD

Gambar 1.2 menggambarkan persentase kreattivitas mahasiswa PG-PAUD FKIP Unsri siklus 1 pertemuan kedua. Pada gambar tersbeut terlihat persentase pada aspek kelancaran sebesar $66,66 \%$, aspek keluwesan sebesar $71,66 \%$, aspek orginalitas sebesar $74,16 \%$, aspek mengelaborasi sebesar $72,5 \%$, aspek sistematis sebesar $69,16 \%$. Pada pertemuan kedua ini aspek yang paling tinggi adalah aspek orginalitas.

\section{SIKLUS II}

\section{Pertemuan 1}

Pada siklus kedua pertemuan pertama adalah menentukan tema cerita rakyat yang akan di implementasikan dalam bentuk tari oleh masing-masing kelompok tari anak dan hasil evluasi kreativitas mahasiswa dapat dilihat berikut ini:

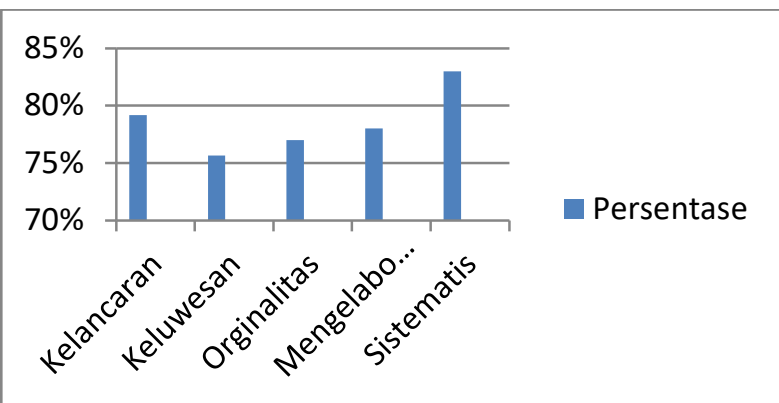

Gambar 1.3 Grafik Peningkatan Kreativitas Mahasiswa PG-PAUD FKIP Unsri

Pada gambar 4.3 terlihat persentase kreativitas mahasiswa PG-PAUD FKIP Unsri. Dalam grafik tersebut terlihat persentase pada aspek kelancaran sebesar 79,16\%, pada aspek keluwesan sebesar $75 \%$, aspek orginalitas sebesar $77 \%$, aspek mengelaborasi sebesar $78 \%$, aspek sistematis sebesar $83 \%$.

\section{Pertemuan 2}

Praktik gerak dasar tari berdasarkan masing-masing tokoh yang ada di cerita berdasarkan unsur gerak tari. Hasil evaluasi kreatiitas mahasiswa dapat dilihat pada grarifik berikut ini:

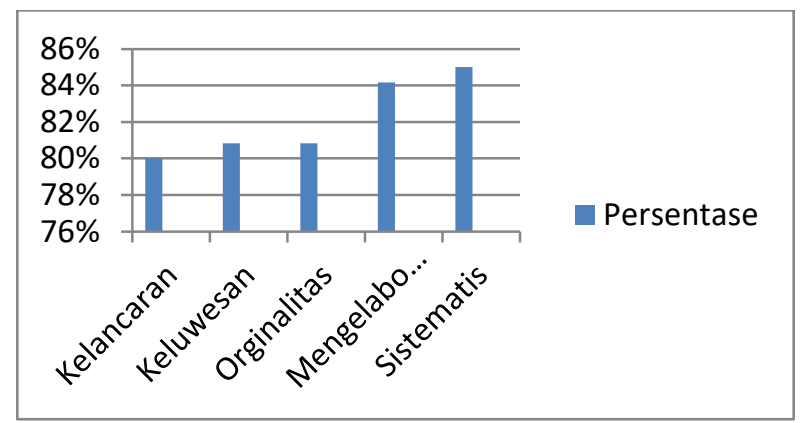

Gambar 1.3 Grafik Peningkatan Kreativitas Mahaiswa PG-PAUD

Pada gambar 4.4 siklus dua pertemuan kedua terlihat peningktan persentase kreativitas. Aspek kelancaran sebesar 80\%, aspek keluwesan sebesar 80,83\%, aspek orginalitas sebesar $80,83 \%$, aspek mengelaborasi sebesar $84,16 \%$, aspek sistematis sebesar $85 \%$.

Berdasarkan analisa data, peneitian ini memperoleh peningkatan kreativitas pada mahaiswa PG-PAUD FKIP Unsri. Hal tersebut dapat dilihat dari grafik peningkatan kreativitas mahasiswa PG-PAUD dari siklus 1 sampai dengan siklus 2: 


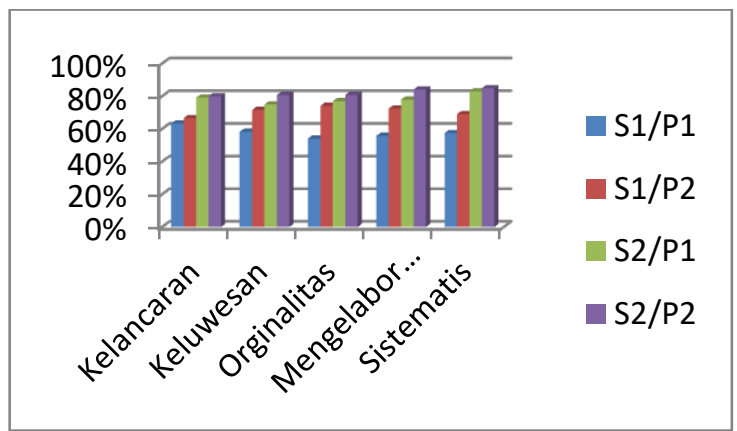

Gambar 1.4 Grafik Peningkatan Kreativitas Mahasiswa PG-PAUD FKIP Unsri

\section{UCAPAN TERIMA KASIH}

Kami sampaikan terima kasih kepada semua pihak yang telah membantu dalam menyelesaikan artikel jurnal ini, mudahmudahan mendapatkan balasan dari Alloh SWT. Amin.

\section{SIMPULAN}

Mata kuliah seni tari dapat meningkatkan kreativitas, terbukti dengan pengamatan yang dilakukan telah mencapai indikator keberhasilan 75\%. Pada siklus 1 pertemuan laspek kelancaran berada pada kategori 63,33\%, keluwesan berada pada kategori $58,33 \%$, orginalitas berada pada kategori 54,16\%, mengelaborasi berada pada kategori 55,83\%, sistematis berada pada kategori $57,5 \%$. Kedua pada siklus pertama pertemuan kedua, pada aspek kelancaran sebesar 66,66\%, aspek keluwesan sebesar $71,66 \%$, aspek orginalitas sebesar $74,16 \%$, mengelaborasi sebesar 72,5\%, sistematis sebesar $69,16 \%$. Ketiga pada siklus 2 pertemuan 1 pada aspek kelancaran sebesar $79,16 \%$, keluwsen sebesar $75 \%$, orginalitas sebesar 77\%, mengelaborasi sebesar $78 \%$, sistematis sebesar $83 \%$. Keempat pada siklus 2 pertemuan 2, aspek kelancaran sebesar $80 \%$, keluwesan sebesar $80,83 \%$, orginalitas sebesar $80,83 \%$, mengelaborasi sebesar $84,16 \%$, dan pada aspek sistematis sebesar $85 \%$

\section{DAFTAR PUSTAKA}

Arikunto, Suharsimi. 2006. Prosedur Penelitian Suatu Tindakan Praktik. Jakarta: Rineka Cipta.

Astuti, A. (2016). Peningkatakan Kemampuan Anak Mengenal Konsep Bilangan
Melalui Permainan Kartu Angka di Kelompok B TK Aisyiyah Pulau Payung Kecamatan Rumbio Jaya.Jurnal Obsesi, 2(1), 90-99

Depdiknas. 2006. Undang-Undang Guru dan Dosen serta Standar Nasional Pendidikan Tahun 2005. Jakarta.Penerbit CV Tamita Utama.

Edi Setyowati, 1986. Pengetahuan Elemen Tari Dan Beberapa Masalah Tari. Jakarta: Direktorat Kesenian.

Fauziddin, M. (2017). Upaya Peningkatan Kemampuan Bahasa Anak Usia 4-5 Tahun melalui Kegiatan Menceritakan Kembali Isi Cerita di Kelompok Bermain Aisyiyah Gobah Kecamatan Tambang. Jurnal Obsesi, 1(1), 42-51

Mills, E Geoffrey E. 2003. Action Research . Ohio: Pearson Merill Pretice Hall.

Muhammad, As'adi. 2010. Bila Otak Kanan dan Otak Kiri Seimbang. Jogjakarta: Diva Press

Munandar, Utami. 1999. Kreativitas dan Keterbakatan. Jakarta: PT. Gramedia Pustaka Utama

Nurmalina, N. (2016). Hubungan Penerapan Bahasa Indonesia dengan Pengembangan Kepribadian Peserta Didik PAUD Kualu Ceria. Jurnal Obsesi, 2(1), 73-78.

Zainal Aqib, 2009. Penelitian Tindakan Kelas untuk Guru, SD, dan TK. Bandung: Yrama widya 